\title{
Varicella zoster gastritis in a bone marrow transplant recipient
}

\author{
W G McCluggage, J D Fox, K E M Baillie, P V Coyle, F G C Jones, M D O’Hara
}

\begin{abstract}
A case is reported of a patient who had previously undergone autologous bone marrow transplantation for recurrent Hodgkin's disease. The patient developed a generalised vesicular skin eruption. The clinical diagnosis was of disseminated shingles. Herpes viral particles were identified within the vesicular fluid by electron microscopy and using a specific monoclonal antibody to varicella zoster virus (VZV), positive immunofluorescence was detected in scrapings from the base of a vesicle. Gastroscopy and biopsy were performed because of severe abdominal pain and vomiting. The histological features were of non-specific active inflammation. Despite the histological absence of viral inclusions electron microscopy of the gastric biopsy revealed the presence of intranuclear herpes viral particles with a diameter of 90-100 nm. VZV specific DNA was detected by the polymerase chain reaction in the gastric biopsy extract. The patient was treated with acyclovir and made a full recovery.
\end{abstract}

(F Clin Pathol 1994;47:1054-1056)

Primary infection with varicella zoster virus (VZV) gives rise to chickenpox, while reactivation of the latent virus in previously infected subjects results in shingles. In developed countries approximately $95 \%$ of healthy adults have been exposed to VZV during childhood. Infection with the virus is not an uncommon complication in immunocompromised patients, including those who have undergone bone marrow transplantation. Atkinson $e a^{1}$ found that nearly $50 \%$ of marrow transplant recipients who survived at least six months developed VZV infection. The overall mortality rate was $8 \%$, all with pneumonia as the primary clinical manifestation. Infection in the immunocompromised subject usually represents reactivation of latent virus. We report the case of a bone marrow transplant recipient with disseminated shingles who developed gastritis, a rarely described complication of VZV infection.

\section{Case report}

A 24 year old man presented in September 1984 with right cervical and axillary lymphadenopathy and splenomegaly. A lymph node was excised and the histological diagnosis was of mixed cellularity Hodgkin's disease. Bone marrow aspirate and trephine biopsy did not show any evidence of Hodgkin's disease. Clinically, the patient was stage IIIA. He underwent a total of eight courses of combined chemotherapy with chlorambucil, vinblastine, procarbazine, and prednisolone. Remission was achieved after the fourth course of treatment and he remained well until January 1992, when he was diagnosed as having left axillary, internal mammary, and para-aortic lymphadenopathy. A further node biopsy confirmed relapse of mixed cellularity Hodgkin's disease. He underwent eight further courses of the same combined chemotherapy regime. Again, remission was achieved after four courses.

In May 1993 the patient underwent an autologous bone marrow transplant because of recurrent Hodgkin's disease. The posttransplant course was largely uneventful. In August 1993, however, he developed a widespread, bilateral vesicular rash over much of his head and trunk. He had had chickenpox as a child and suffered one prior episode of shingles in 1985. The clinical diagnosis was of disseminated shingles. He was commenced on acyclovir $500 \mathrm{mg}$ intravenously thrice daily.

Before the development of the skin rash, the patient had developed crampy upper abdominal pain with associated vomiting. An oesophagogastroduodenoscopy (OGD) was performed and revealed patchy gastritis throughout the gastric body and antrum. Multiple areas of superficial erosion were present. The oesophagus and duodenum were normal. Gastric biopsy specimens were taken for histological examination. The abdominal symptoms settled after treatment with acyclovir and the patient made a full recovery.

\section{Methods}

Vesicular fluid was prepared routinely for electron microscopic examination and scrapings from the base of a vesicle were stained with an in-house VZV specific monoclonal antibody using an indirect immunofluorescence technique.

Gastric biopsy specimens were embedded in paraffin wax and sections stained with haematoxylin and eosin, and Giemsa. Immunohistochemistry was carried out using a standard streptavidin-biotin peroxidase technique with antibodies against herpes simplex virus types 1 (HSV-1) and 2 (HSV2), cytomegalovirus (CMV), and VZV. A portion of the paraffin wax embedded block was dewaxed and prepared routinely for electron microscopy. Ultrathin sections were stained with uranyl acetate and lead citrate.

The remainder of the tissue was examined 


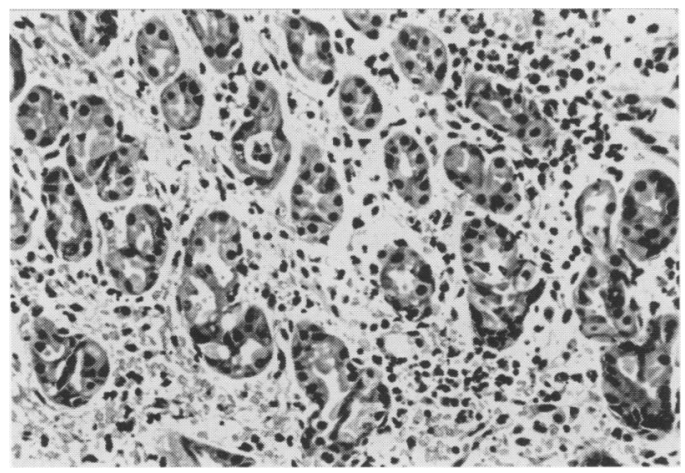

Figure 1 Active gastritis with polymorphs infiltrating gastric glands.
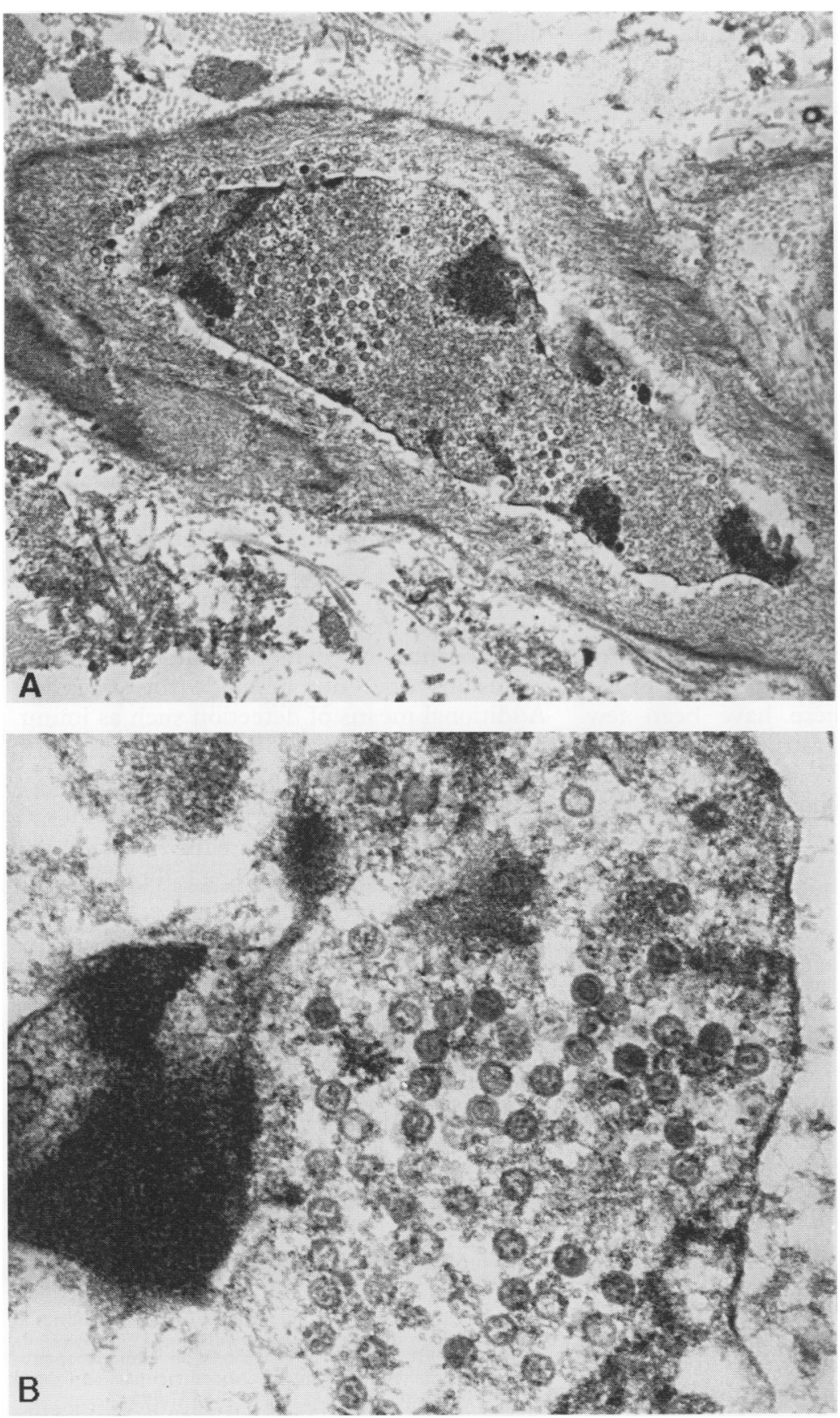

Figure 2 (A) Myofibroblast containing intranuclear viral particles belonging to the herpes group $(\times 11280)$. (B) Higher power showing intranuclear herpes viral particles $(\times 39800)$. using the polymerase chain reaction (PCR). The tissue block was dewaxed by being treated with two changes of xylene, washed in absolute and then $75 \%$ ethanol solutions, rinsed in sterile water, and $200 \mu \mathrm{l}$ extraction buffer containing $0.01 \mathrm{M}$ TRIS ( $\mathrm{pH} 8$ ), 0.01 $M$ EDTA, $0.01 \mathrm{M}$ sodium chloride, 200 $\mu \mathrm{g} / \mathrm{ml}$ proteinase $\mathrm{K}$, and $0.5 \%$ sodium dodecyl sulphate (SDS). Protein digestion was achieved by incubating the mixture at $37^{\circ} \mathrm{C}$ for 24 hours; proteinase $\mathrm{K}$ was inactivated by boiling the sample for 10 minutes. The sample was then cooled on ice, spun at $15000 \times$ $g$ for 10 minutes to pellet any residual undigested material and 10-fold dilutions of the supernatant were prepared for analysis by PCR

Viral DNA sequences were detected using nested PCR. Oligonucleotide primers specific for VZV, CMV, and HSV-1 were designed using available viral sequences and published PCR data. The oligonucleotide primers used in the first round PCR reactions for amplification of VZV gene 29 and CMV gene $B$ were adapted from those published previously. ${ }^{2}$ A second pair of primers for amplification of first round VZV and CMV specific PCR products have been designed and used for the sensitive detection of these viral sequences in clinical samples. ${ }^{3}$ Oligonucleotide primers specific for HSV-1 gene $D$ have been described before. ${ }^{4}$

PCR was carried out in a total volume of $50 \mu \mathrm{l}$ with final concentrations of $1.5 \mathrm{mM}$ $\mathrm{MgCl}_{2}, 50 \mathrm{mM} \mathrm{KCl}, 10 \mathrm{mM}$ TRIS (pH 8.3), $1.25 \mathrm{mM}$ dNTP, 1.25 units Ampli Taq DNA polymerase (Perkin Elmer, Beaconsfield, England), and $100 \mathrm{ng}$ of each primer, as described previously. ${ }^{3}$ One microlitre of the diluted tissue extract was added and the mixture overlaid with mineral oil. Samples were subjected to denaturation for four minutes at $94^{\circ} \mathrm{C}$ followed by 35 cycles at $94^{\circ} \mathrm{C}$ for two minutes (denaturation), $60^{\circ} \mathrm{C}(\mathrm{VZV}$ and HSV-1) or $58^{\circ} \mathrm{C}$ (CMV) for two minutes (annealing), and $72^{\circ} \mathrm{C}$ for one minute (extension), with an additional seven minute extension in the last cycle. After completion of the 35 cycles, $1 \mu \mathrm{l}$ of the first round product was transferred to the nested PCR mixture containing the internal primers. The second round PCR reaction was carried out in a total volume of $25 \mu \mathrm{l}$ under the same conditions as the first amplification, except that the primer concentration was doubled and the initial four minute denaturation cycle at $94^{\circ} \mathrm{C}$ was omitted. The annealing temperature for all three viruses was reduced to $50^{\circ} \mathrm{C}$ for the nested PCR reaction and 25 cycles were sufficient for the detection of the second round products. Each nested PCR product $(10 \mu \mathrm{l})$ was subjected to electrophoresis on a $3 \%$ agarose gel, stained with ethidium bromide, visualised with ultraviolet light, and photographed.

\section{Results}

Electron microscopy of the vesicular fluid confirmed the presence of viral particles belonging to the herpes group and positive 
immunofluorescence was obtained in the scrapings from the vesicular base using the VZV monoclonal antibody.

On histology, superficial mucosal erosion and active gastritis with focal collections of polymorphs infiltrating superficial gastric glands were present (fig 1). Helicobacter organisms were not found on sections stained using haematoxylin and eosin or Giemsa. Despite examination of multiple levels, intranuclear inclusions were not seen. Immunohistochemical staining for $\mathrm{HSV}-1$ and -2 , CMV and, VZV was negative.

Ultrastructural examination of the section of dewaxed specimen prepared for electron microscopy revealed occasional myofibroblastic cells, in which collections of viral capsids, $90-100 \mathrm{~nm}$ in diameter, were observed (fig 2). Some capsids contained a core of electron dense material, presumably nucleic acid. These features are characteristic of the herpes group of viruses. Occasional viral capsids were also present within the cell cytoplasm. On PCR, using the above method, VZV, but not HSV-1 or CMV, specific DNA was detected in the gastric biopsy extract. The VZV specific DNA was detected down to a 1 in 100 dilution of the tissue extract.

\section{Discussion}

The present case had chickenpox as a child, one previous episode of shingles, and was diagnosed as having disseminated shingles, an uncommon occurrence in immunocompetent but not in immunocompromised patients. ${ }^{5}$ Complications of chickenpox include pneumonia, ${ }^{1}$ encephalitis, ${ }^{1}$ hepatitis, ${ }^{6}$ thrombocytopenia, and bleeding disorders. ${ }^{7}$ Occasional cases of abdominal pain and appendicitis have been reported in children with chickenpox. ${ }^{8}$ These reports, however, have not adequately shown that VZV was the cause of the appendicitis. Indeed, there have been few published reports of gastric or intestinal involvement in which VZV infection has been the cause. In 1971 Khilnani et al ${ }^{5}$ reported necropsy findings in a 61 year old woman with an 18 year history of polycythaemia rubra vera. The patient had had VZV infection of the inframammary region of the chest and numerous circular areas of ulceration with a haemorrhagic base were identified within the stomach at necropsy. Scattered similar lesions were identified within the small and large intestine. Histological examination disclosed inclusion bodies in epithelial and inflammatory cells. Herpes virus particles, however, were not actually found within the intestine and VZV was not conclusively proved to be the cause of the gastric lesions.

In 1990 Sherman et $a l^{9}$ reported a fatal case of varicella in a 38 year old steroid dependent asthmatic man who developed a generalised vesicular eruption following exposure to a relative who had developed chickenpox. Necropsy revealed that the mucosal surface of the small bowel was covered by small, punctate haemorrhagic ulcerations. Fluorescence staining of these lesions with a fluorescein labelled monoclonal antibody against VZV revealed the presence of virus. The stomach and large bowel were histologically normal. In both these reports there was evidence of disseminated VZV infection with involvement of skin, intestine, liver, and lungs. ${ }^{59}$

Occasional cases of gastritis associated with HSV have also been reported. In 1977 Sperling and Reed ${ }^{10}$ reported the case of a 58 year old woman with multiple raised plaques in the antrum of the stomach. Brush specimens of gastric mucosa revealed cells with "ground glass" nuclei and well formed eosinophilic intranuclear inclusion bodies surrounded by halos. These authors regarded these changes as pathognomonic of HSV infection; however, they did not reveal the presence of virus by immunofluorescence or electron microscopic examination. HSV infection is, of course, well described in the oesophagus.

VZV, CMV, and HSV particles cannot be distinguished by electron microscopy. However, in the present case VZV DNA was detected in the gastric biopsy extract by PCR, confirming that this virus, and not another member of the herpes group of viruses, was the cause of gastritis. The fact that VZV could not be demonstrated in the gastric biopsy using immunohistochemistry may be explained by the relative insensitivity of immunoperoxidase techniques compared with PCR for detecting small numbers of viral particles.

While most cases of VZV infection follow a benign course, it is the immunocompromised patient who will suffer the highest morbidity and mortality. Gastric involvement, although rare, can occur. The histological findings may be non-specific, as in the present case, and the absence of demonstrable intranuclear inclusions does not preclude the diagnosis. Additional means of detection such as immunohistochemistry or PCR may be required to demonstrate the presence of viral particles.

1 Atkinson K, Meyers JD, Storb R, Prentice RL, Thomas ED. Varicella zoster virus infection after marrow transplantation for aplastic anaemia or leukaemia. Transplantation 1980;29:47-50.

2 Mahalingham $R$, Wellish $M$, Wolf $W$, Dueland AN, Cohrs R, Vajai A, et al. Latent Varicella-Zoster viral DNA in the human trigeminal and thoracic ganglia. $N$ Engl f Med 1990;323:627-31.

3 Wakefield AJ, Fox JD, Sawyerr AM, Taylor JE, Sweenie $\mathrm{CH}$, Smith $\mathrm{M}$, et al. Detection of herpes virus DNA in the large intestine of patients with ulcerative colitis and Crohn's disease using the nested polymerase chain reaction. $f$ Med Virol 1991;38:183-90.

4 Aurelius E, Johansson B, Skoldenberg B, Staland A, Forsgren $M$. Rapid diagnosis of herpes simplex encephalitis by nested polymerase chain reaction of encephalitis by nested polymerase chain

5 Khilnani MT, Keller RJ. Roentgen and pathological changes in the gastrointestinal tract in herpes zoster changes in the gastrointestinal tract in herpes zoster generalizata: a unique $1971 ; 38: 303-10$.

6 Patti ME, Selvaggi KJ, Kroboth FJ. Varicella hepatitis in the immunocompromised adult: a case report and review of the literature. Am $\mathcal{F}$ Med 1990;88:77-80.

7 Espinoza C, Kuhn C. Viral infection of megakaryocytes in varicella with purpura. Am $\mathcal{F}$ Clin Pathol 1974;61:203-8.

8 Morgan ER, Smalley LA. Varicella in immunocompromised children: incidence of abdominal pain and organ involvement. Am ₹ Dis Child 1983:137:883-5.

9 Sherman RA, Silva J, Gandoor-Edwards R. Fatal varicella in an adult: Case report and review of the gastrointestinal complications of chickenpox. Rev Infect Dis 1991;13:424-7.

10 Sperling HV, Reed WG. Herpetic gastritis. Dig Dis 1977; 22:1033-4. 